\title{
The motives for seeking dental health services in a sample of children attending a College of Dentistry
}

\author{
Erbil, Iraq
}

Alaa Mahmud Mustafa ${ }^{(1)}$; Heran Ibrahim Hassan $^{(1)}$; Fighan Jalal Huseen $^{(1)}$

\begin{abstract}
Background and Objectives: The chief complaints of the patients are essential components, being useful for several reasons, including monitoring of oral health services and measuring the effectiveness of the oral health awareness programs. The objective of the study was to explore the common chief complaints of patients seeking treatment and distribution of cases according to the demographic data among patients attending a dental college in Erbil, Iraq.

Patients and methods. The age, gender, and the chief complaints or the main reason for the visit were recorded for each consecutive patient of a total of 1233 patients who visited the oral hygiene clinics in the College of Dentistry at Hawler Medical University (Erbil city, Iraq), from October 2016 to June 2017 were recruited. Patients at the age of 3 - 14 years old. The chisquare test was used to find any statistical association between the variables. $P$ value of less than 0.01 was considered statistically significant.

Results: The pain was found to be the most common chief complaint reported by $51.1 \%$ of the patients. Followed by oral hygiene reported by $26 \%$, among which $658(53.4 \%)$ were males and 575 (46.6\%) were females. When the age groups were considered separately, "toothache" or pain was the most common chief complaints reported by all ages except for the $<5$ years' group patients for whom that oral hygiene was the most common chief complaint. In the age group of 10-14 years, in addition to pain and oral hygiene, significantly more subjects complained of orthodonitc treatment need.

Conclusion: Chief complaints denote the demand for dental care and thus, helps in proper planning of the public dental health care system. So the reason for dental visit varies across different age groups and to some extent, gender differences was a considering issue.
\end{abstract}

Keywords: Distribution, Paedodontics, Diagnosis, Dental chief complaints.

${ }^{(1)}$ College of Dentistry, Hawler Medical University, Erbil, Iraqi Kurdistan Region.

Correspondence: Alaa Mahmud Mustafa, email: allaafaqi@yahoo.com

\section{Introduction}

One of the important milestones in child's life is the dental visit. The dental visit should be done in correct time since it plays an essential part in the child's oral health. ${ }^{1-16}$ The child's first dental visit helps in determining the quality of the preventive dental care that the child will receive and, thus, the future oral health of the child. ${ }^{1}$ A chief complaint is defined as a subjective statement provided by a patient that describes the most significant or serious symptoms or signs of illness or dysfunction that caused him or her to seek a health care provider. $^{3}$
Oral health care is becoming more complex, with the diagnosis and planning of treatment depending entirely on the chief complaint reported by the patient clinically, ${ }^{1,2}$ research and administrative objectives of dental practices rely on the presence of an easily identifiable and clear chief complaint. ${ }^{2}$ They do not seek treatment for dental illness until considerable time has elapsed and the symptoms have become extremely severe, lack of knowledge, fear of dental treatment includes fear of pain, fingers or needles in the mouth, sedation, lying on dental unit, sound of dental instruments, ${ }^{17}$ and even 
lack of motivation of seeking dental treatment form some of the obstacles in seeking necessary oral health care. This leads to serious dental problems. ${ }^{6,17}$ The ignorance of seeking dental treatment at initial stages of disease leads the tooth to an advanced stage of dental decay which is commonly beyond repair and consequently these delays lead to extraction of the tooth. ${ }^{18}$ Patients who suffer from severe dental and facial pain that is not controllable by over-the-counter preparations, as well as the dental and soft tissues, acute infections, uncontrollable dental hemorrhage, dental trauma or rapidly increasing facial swellings require urgent dental care. $^{4}$

Studies show that the most emergency visit of the patients to seek dental clinic results from dental decay. ${ }^{1,5}$ The preventive goals during an early dental visit may include guidance on oral hygiene, diet, nonnutritive sucking habits and its risk of developing malocclusion. Education regarding traumatic injuries and its first aid management can be done. ${ }^{1}$

It was found that only very few studies were made on the chief complaints of dental patients and there was no published report about Kurdistan-Iraq. Hence, this study was undertaken to determine the common chief complaints of dental patients among patients attending the Department of Peadodontics, Orthodontics and Preventive Dentistry, College of Dentistry, Hawler Medical University, Erbil, Iraq.

\section{Materials and methods}

Study design. Descriptive cross sectional study. A total of 1233 patients who visited the Peadodontics clinics in the College of Dentistry at Hawler Medical University (Erbilcity, Iraq), from October 2016 to June 2017 were recruited, age from 3 to 14 years old. The data extraction forms included demographic variables (age and sex) and chief complaints. Chief complaints included the reason(s) why patients sought dental care. Chief complaints were divided into categories as pain, orthodontic treatment need, esthetics, oral hygiene, swelling and tooth mobility. The dental examination was performed by using standard probe, dental mirrors with artificial light. A routine dental checkup considered for any patient who visits the dentist every six months to assess the current oral health clinical examination.

Statistical analysis. Data were analyzed using the Statistical Package for Social Sciences (SPSS, version 22). Chi square test of association was used to compare proportions. Fisher's exact test was used when the expected count of more than $20 \%$ of the cells of the table was less than 5. A $P$ value of $\leq 0.01$ was considered statistically significant.

\section{Results}

Of the 1233 Patients who participated in the survey, $658(53.4 \%)$ were males and $575(46.6 \%)$ were females (Table 1$)$. In age $5-9$ years were the most percentage $69.4 \%$, while in age group 10-14 were $28.1 \%$ and the fewer subjects participated were $2.5 \%$ in $<5$ years (Figure 1 ).

Figure (2) shows the percentage distribution of the chief complaints. Overall, the most common chief complaint reported was "pain" reported by $51.1 \%$ of the subjects. The second and third most common chief complaints reported were oral hygiene reported by of $26.0 \%$ the subjects and "oral swelling" reported by $12.3 \% \%$ of the subjects respectively. Orthodontic treatment need reported by $7.1 \%$, esthetics reported by $2.5 \%$ and tooth mobility reported by $1 \%$.

Table 1: Percentage distribution of subjects according to age group and gender.

\begin{tabular}{|c|c|c|c|}
\hline \multirow{2}{*}{ Age } & \multicolumn{2}{|c|}{ Gender } & \multirow{2}{*}{ Total } \\
\cline { 2 - 4 } & Male & Female & \\
\hline \multirow{2}{*}{$<5$} & 15 & 16 & 31 \\
\cline { 2 - 4 } & $48.4 \%$ & $51.6 \%$ & $100.0 \%$ \\
\hline \multirow{2}{*}{$5-9$} & 456 & 400 & 856 \\
\cline { 2 - 4 } & $53.3 \%$ & $46.7 \%$ & $100.0 \%$ \\
\hline \multirow{2}{*}{$10-14$} & 187 & 159 & 346 \\
\cline { 2 - 4 } & $54.0 \%$ & $46.0 \%$ & $100.0 \%$ \\
\hline \multirow{2}{*}{ Total } & 658 & 575 & 1233 \\
\cline { 2 - 4 } & $53.4 \%$ & $46.6 \%$ & $100.0 \%$ \\
\hline \multirow{2}{*}{ Pearson Chi-Square } & \multicolumn{3}{|c}{0.829} \\
\hline
\end{tabular}




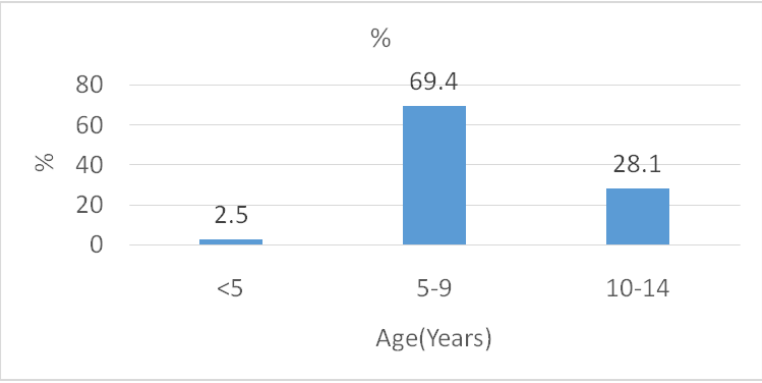

Figure 1: Percentage of patients age participated in study.

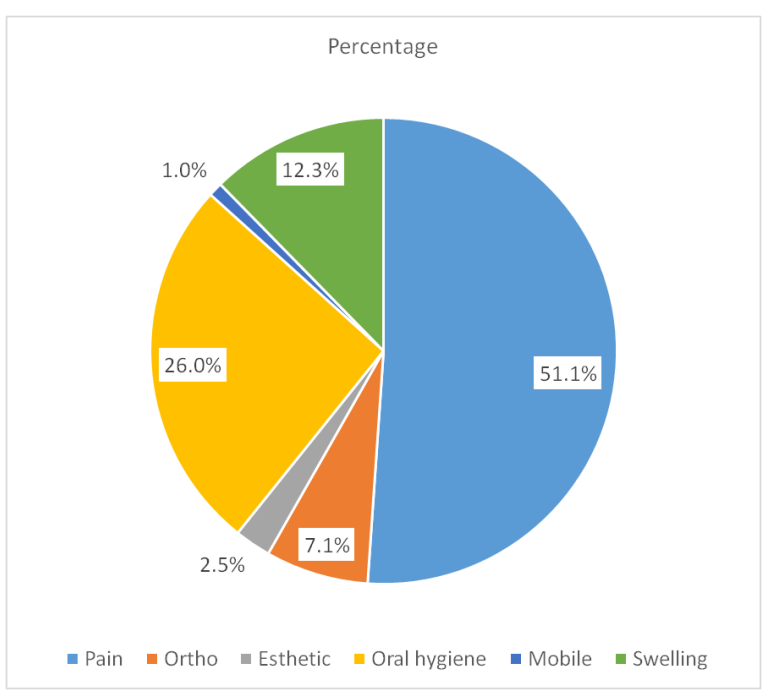

Figure 2: Distribution of Chief complaints of patients.

Distribution of the chief complaints according to gender. Table 2 shows there are not statistically significant differences between sexes. Table 3 shows percentage distribution of the chief complaints according to age group. When the age groups were considered separately, "toothache" or pain were the most common chief complaint reported by all ages except in the $<5$ years, that dental oral hygiene $45.2 \%$ was the most common chief complaint reported. In the age $<5$ years significantly more subjects complained of oral hygiene, pain and swelling $(P<0.001)$, whereas no subjects complained of orthodonitc treatment need, tooth mobility and esthetic (Table 3). Among the age group of 5-9 years, significantly more subjects complained of "toothache" ( $P$ $<0.001$ ) was $58.1 \%$ and oral hygiene $25.9 \%$, whereas fewer subjects complained of oral swelling, orthodonitc treatment need, esthetic and tooth mobility $10 \%$,
$3.5 \%, 1.9 \%, 6 \%$ respectively. In the age group of 10-14 years, in addition to pain $35.3 \%$, and oral hygiene $24.3 \%$, significantly more subjects complained of oral swelling, orthodonitcs treatment need, esthetic and tooth mobility $17.3 \%, 16.8 \%$, $4.3 \%, 2 \%$ respectively $P<0.001$ (Table 3 ) .

Table 2: Distribution of the chief complaints according to gender.

\begin{tabular}{|c|c|c|c|}
\hline \multirow{2}{*}{ Chief Complaint } & \multicolumn{2}{|c|}{ Gender } & \multirow{2}{*}{ Total } \\
\cline { 2 - 3 } & Male & Female & \\
\hline \multirow{2}{*}{ Pain } & 339 & 291 & 630 \\
\cline { 2 - 4 } & $51.5 \%$ & $50.6 \%$ & $51.1 \%$ \\
\hline $\begin{array}{c}\text { Orthodontic } \\
\text { treatment need }\end{array}$ & 53 & 35 & 88 \\
\cline { 2 - 4 } & $8.1 \%$ & $6.1 \%$ & $7.1 \%$ \\
\hline \multirow{2}{*}{ Esthetic } & 20 & 11 & 31 \\
\cline { 2 - 4 } Oral hygiene & $3.0 \%$ & $1.9 \%$ & $2.5 \%$ \\
\cline { 2 - 4 } & 168 & 152 & 320 \\
\hline \multirow{2}{*}{ Tooth Mobitily } & $25.5 \%$ & $26.4 \%$ & $26.0 \%$ \\
\cline { 2 - 4 } & 4 & 8 & 12 \\
\hline \multirow{2}{*}{$\begin{array}{c}\text { Oral } \\
\text { Swelling }\end{array}$} & 74 & $1.4 \%$ & $1.0 \%$ \\
\cline { 2 - 4 } & $11.2 \%$ & $13.6 \%$ & $12.3 \%$ \\
\hline
\end{tabular}

Table3: Percentage distribution of the chief complaints according to age group.

\begin{tabular}{|c|c|c|c|c|}
\hline \multirow{2}{*}{ Chief complain } & \multicolumn{3}{|c|}{ Age } & \multirow{2}{*}{ Total } \\
\hline & $<5$ & $5-9$ & $10-14$ & \\
\hline \multirow{2}{*}{ Pain } & 11 & 497 & 122 & 630 \\
\hline & $35.5 \%$ & $58.1 \%$ & $35.3 \%$ & $51.1 \%$ \\
\hline \multirow{2}{*}{$\begin{array}{c}\text { Orthodontic } \\
\text { treatment } \\
\text { need }\end{array}$} & 0 & 30 & 58 & 88 \\
\hline & $0.0 \%$ & $3.5 \%$ & $16.8 \%$ & $7.1 \%$ \\
\hline \multirow{2}{*}{ Esthetic } & 0 & 16 & 15 & 31 \\
\hline & $0.0 \%$ & $1.9 \%$ & $4.3 \%$ & $2.5 \%$ \\
\hline \multirow[b]{2}{*}{ Oral hygiene } & 14 & 222 & 84 & 320 \\
\hline & $45.2 \%$ & $25.9 \%$ & $24.3 \%$ & $26.0 \%$ \\
\hline \multirow{2}{*}{$\begin{array}{l}\text { Tooth } \\
\text { Mobility }\end{array}$} & 0 & 5 & 7 & 12 \\
\hline & $0.0 \%$ & $.6 \%$ & $2.0 \%$ & $1.0 \%$ \\
\hline \multirow{2}{*}{$\begin{array}{c}\text { Oral } \\
\text { Swelling }\end{array}$} & 6 & 86 & 60 & 152 \\
\hline & $19.4 \%$ & $10.0 \%$ & $17.3 \%$ & $12.3 \%$ \\
\hline \multirow{2}{*}{ Total } & 31 & 856 & 346 & 1233 \\
\hline & $100.0 \%$ & $100.0 \%$ & $100.0 \%$ & $100.0 \%$ \\
\hline
\end{tabular}




\section{Discussion}

The chief complaints of patients are considered significant because they help dentist to quickly assess what is important to the patient. ${ }^{19}$ In the present study, the most common reason for demanding dental treatment was "toothache" or pain $51.1 \%$ which is in agreement with the study that was done by Al-Johani et al, who examined 3566 dental patients. They found that the most common chief complaints were dental pain $(35.4 \%){ }^{2}$ Dhaimade and Banga in India performed a study on 300 randomly selected patients reporting to Nair Hospital Dental College ranging and found the most common chief complaint recorded among the dental patients was dental pain, this was followed by swelling, mobility and tooth replacement. ${ }^{6}$ So our result was in accordance with the findings other researchers. ${ }^{6,8,9,11,12,20}$ Findings of this study reveal that most people appear to seek treatment only when acute disturbing symptoms such as pain is apparent. Demanding treatment at late stages may relate to several psychosocial factors such as dental anxiety states, financial costs, perceptions of need, and lack of access. ${ }^{8}$

While the second chief complaints was oral hygiene $26 \%$ of the reasons which in line with the finding of John etal. ${ }^{21}$ In our study this finding indicates high dental educational level among Erbil city civilization. It is recommended for every person to visit the dentist every six months for oral hygiene, ${ }^{17}$ because most dental problems can be prevented with regular dental care, our finding coincide with the finding of many studies. ${ }^{1,11}$ Genderwise distribution of our study run parallel with a study in that male patients are more than female patients. ${ }^{12}$ and disagreed with previous research., ${ }^{2,6,11}$ Most of the children where brought for oral hygiene in the age group $<5$-year-old were $45.2 \%$ for preventive treatment. This could be due to the awareness regarding dental health among the parents, in the region and children in this age were under control from parents. Our finding was compatible with other studies. ${ }^{1,17}$

A higher proportion of children (69.4\%) were from 5 to 9 years' old. This is in agreement with results of studies from ${ }^{12,13}$ and most of them had pain in their teeth this is due to that in these age were independent children and, this is worrying, trend given the importance of these teeth in masticatory function and in preserving space for the successor teeth. ${ }^{8}$ The 5-9years old was the predominant age group attending diagnosis clinic. This followed by 10-14 years' age group. In addition to pain, the orthodontic treatment need and esthetics were part of common chief complaints in these age group may be due to that they are young and deal with appearance and more aware about their appearance, this result was unclosing to other reported results about chief complaints. ${ }^{8,13}$ One of the limitations of this study is that it is conducted only in one public dental hospital without collecting socioeconomic details of the patients not having a random sample might not represent the entire population of Erbil city which in turn affect the generalization of our results, so caution is necessary before drawing conclusions. ${ }^{14}$ Also, the actual dental treatment needs of the patients and the underlying cause for the chief complaints were not assessed. So the perceived need could not be compared with the normative need of the study population. Accurate and consistent documentation of hospital records may facilitate complete data retrieval for large scale hospital-based retrospective studies. ${ }^{.4}$

\section{Conclusion}

Our study focused on children patients ranging from 3-14 years old age to emphasize the importance of early dental visits, chief complaint and regular check-ups should also be emphasized through different methods of oral health education. For instance, mass media campaigns and oral health education programs based on community, kindergartens and schools could be excellent choices recorded, in our study was dental pain reported $51.1 \%$ followed by oral hygiene was $26 \%$, oral swelling $12.3 \%$, orthodontics treatment need $7.1 \%$, esthetics $2.5 \%$ and tooth mobility $1.0 \%$, male patients more than female patients. So the reason for dental visit varies across different age groups and to some extent, gender differences are also noted. Multicentric 
studies about chief complaints will give an idea about the actual demand for dental care. This would be helpful for proper planning of the dental health care system at the national level with limited financial resources.

\section{Conflict of interest}

\section{Conflict of interest}

The authors reported no conflict of interests

\section{Acknowledgments}

We would like to thank children and their parents for giving us access to conduct this study. We also like to acknowledge the help and contribution of the doctors and other assisting staff.

\section{References}

1.Poojashree B, Somasundaram S. Causes for visiting dental clinic. J Pharm Sci \& Res 2015; 7 (9):727-28.

2.Al-Johani K, Lamfon $\mathrm{H}$, Abed $\mathrm{H}$, Beyari $\mathrm{M}$. Common chief complaints of dental patients at Umm AL-Qura University, Makkah city, Saudi Arabia. OHDM. 2017; 16(3):1-4.

3.Greenberg MS, Glick M. Burket's Oral Medicine: Diagnosis and Treatment. $10^{\text {th }} \mathrm{ed}$. BC Decker INC. 2003.

4.Tulip DE, Palmer NO. A retrospective investigation of the clinical management of patients attending an out of hours dental clinic in Merseyside under the new NHS dental contract. Br dent J. 2008; 205 (12):659-64.

5.Quinonez C, Gibson D, Jokovic A, Locker D. Emergency department visits for dental care of nontraumatic origin. Community Dent Oral Epidemiol. 2009; 37(4):366-71.

6.Dhaimade PA, Banga KS. Evaluation of chief complaints of patients and prevalence of selfmedication for dental problems: An institutional study. Int J Community Med Public Health 2018; 5 (2):674-81.

7.World Health Organization. Constitution of the World Health Organization - Basic Documents, Forty-fifth edition, Supplement, 2006.

8. Maheswaran T, Ramesh V, Krishnan A, Joseph J. Common chief complaints of patients seeking treatment in the government dental institution of Puducherry, India. J Indian Acad Dent Spec Res 2015; 2:55-8.

9.Mosha HJ, Ngilisho LA, Nkwera H, Scheutz F, Poulsen $\mathrm{S}$. Oral health status and treatment needs in different age groups in two regions of
Tanzania. Community Dent Oral Epidemiol. 1993; 22:307-10.

10.Oginni AO. Dental care needs and demands in patients attending the dental hospital of the Obafemi Awolowo University Teaching Hospital's Complex Ile-Ife, Nigeria. Niger J Med 2004; 13:339-44.

11.Abdullah BA, Al-Tuhafi AA. Chief complaints of patients attending college of dentistry at Mosul University. Al-Rafidain Dent J 2007; 7:201-5.

12.Shqair AQ, Gomes GB, Oliveria A, Goettems ML, Romao AR, Schardozim LR, Bonow MLM, Torriani $D D$. Dental emergencies in a university pediatric dentistry clinic: A retrospective study. Barz. Oral Res. 2012; 26(1):50-6.

13.Ansari SH., AL-Saffan A, AL-Dhubaiban D, Turkistani OY, AL-Khalaf R, AL-Assaf D. Prevalence of chief complaints among pediatric dental patients in Saudi population, study done in Riydh college of Dentistry and pharmacy, SaudiArabia. Research and Reviews: Journal of Dental sciences. 2016; 4(4):58-62.

14.Masiga MA. Presenting chief complaints and clinical characteristics among patients attending the department of pediatric dentistry clinic at the university of Nairobi dental hospital. East Afr Med J. 2005; 82:652-5.

15. Hoeft KS, Barker JC, Masterson EE. Maternal beliefs and motivations for first dental visit by low-income Mexican American children in California. Pediatr Dent. 2011;33(5):392-8.

16. Hussein AS, Abu Hassan MI, Schroth RJ, Ghanim AM. Par-ent's Perception on the Importance of their children's First dental visit (A cross-sectional Pilot study in Malysia). J Oral and dental Res. 2013; 1(1):17-25.

17.Abbas H, Roshan R, Nasir MZ. Awareness and health seeking behaviour of parents regarding their children's oral health and, professional dental care in islamabad, Pakistan. Pakistan Oral \& Dental Journal. 2017;37(4).

18.Tanwir F, Altamash M, Gustafsson A. Perception of oral health among adults of Karachi. Oral Health Prev Dent. 2006; 4:83-9.

19.GroverV,Malhotra R, Kapoon A, Kaur G, Kaur RK, Sahota JK. Chief complaints of patients seeking treatment for Periodontitis. Int Dent J Students Res. 2013; 5(1):19-24.

20.Xu M, Yan C, Sun X, Cheng M, Xie Y, Si Y. Oral health service utilization patterns among preschool children in Beijing, China. BMC Oral Health. 2018; 18(31).

21.John JR, Mannan H, Nargundkar S, D'Souza M, Do LG, Arora A. Predictors of dental visits among primary school children in the rural Australian community of Lithgow. BMC Health Serv Res. 2017; 17(1): 264. 